\title{
Compositional Studies on Some Additive Concentrations Found in Meat Products Marketed in a Regional Area
}

\author{
Marian MIHAIU ${ }^{1}$, Alexandra TĂBĂRAN ${ }^{1 *}$, Romolica MIHAIU ${ }^{2 *}$, Sorin Daniel DAN ${ }^{1}$, Oana REGET ${ }^{1}$, Ionuț \\ CORDIŞ ${ }^{1}$, Darius CORDEA ${ }^{1}$, Carmen MUREŞAN ${ }^{1}$ \\ ${ }^{1}$ Faculty of Veterinary Medicine, University of Agricultural Sciences and Veterinary Medicine, Mănăştur \\ Street, no.3/5, Cluj-Napoca, Romania; \\ ${ }^{2}$ Department of Food Management, Babes-Bolyai University Cluj-Napoca, Romania. \\ Corresponding author: lapusan_alexandra@yahoo.com
}

Bulletin UASVM Veterinary Medicine 72(1) / 2015,

Print ISSN 1843-5270; Electronic ISSN 1843-5378

DOI:10.15835/buasvmcn-vm: 10567

\begin{abstract}
Food chemical composition of additive substances concentration has become an important issue in this era of globalization. Growing economic interest of producers in achieving increased quantity without considering the quality of products has aroused the interests of consumers at the exact knowledge of the nutritional values of purchased products and the risks to which they are liable.

The aim of this study was to evaluate the concentration of various additives used in the processing of meat products, based on classical biochemical methods.

The material consisted of 107 products ranging from fresh meat purchased from supermarkets and markets found in a regional area. The wide variation in additive values according to the product type revealed the possible healthier products for human consumption. When analyzing additives' concentrations (nitrites $\mathrm{mg} / \mathrm{kg}$, nitrates $\mathrm{mg} / \mathrm{kg}$ ) we found full compliance with the maximum permissible concentrations. Only one sample revealed higher values than the accepted limit of $3 \%$. We concluded that in order to ensure the safer consumption of meat products, biochemical analyses to determine these additives' concentrations, are needed to made on a regular basis.
\end{abstract}

Keywords: additive, nitrate, nitrite, sodium chloride.

\section{INTRODUCTION}

Nowadays the consumers' concern on the compositional quality and the potential harmful factors for human health found in meat products, is growing. There is a visible tendency also for the modernization of the growth systems, processing technologies and globalization at a high level (EFSA, 2010).

The compositional and nutritive quality of the meat products is directly influenced by the main biochemical compounds found in the raw meat that is used for processing. Another relevant aspect is the nature and amount of additives used for preservation, taste, binding etc. The safe amount for additive intake is already established, due to the fact that some food preservatives consumed in inappropriate quantities might lead to side effects or long term repercussions on human health (Iammarino, 2014). For this matter there is a specific legislation adopted by the European Union in which the specific conditions and amounts are stipulated. These rules are included in several European Parliament and Council Directives (Directives 95/2/EC and 2006/52/EC).

There are a number of methodologies for determining preservatives, based on separation, identification, chromatography, electrophoresis etc. (Fazio and Warner 1990; Karovicová and Simko 2000; Wood et al., 2004; Ruiter and Bergwerff 2005; Jiménez Colmenero and Blazquez 2007). In 
what concerns the most frequently used analytical methods for detecting the food additives the infrared spectroscopy is the most prevalent one. It is highly used in the food safety laboratories due to its accuracy and rapidity. Also, there are now in continuous development the molecular methods for the identification of vegetal compounds, replacing little by little the classical ones.

The aim of this paper was to evaluate the concentration of additives used in the processing of meat products, based on classical biochemical methods.

\section{MATERIALS AND METHODS}

The material that was used for this study was represented by 107 meat product samples from the following sorts: 40 minced meat samples (beef and pork meat or beef and sheep meat), 32 samples of baloney and 35 samples of sausages. All of the samples were labeled properly, stating also the additives amounts. The samples were collected from the hypermarkets found in the Transylvania area and from different large-unit producers.

The nitrites determination $\left(\mathrm{NO}_{2}^{-}\right)$

The nitrites were determined through Griess method. The principle of the method was based on the fact that nitrites combine in an acid environment with a primary aromatic amine, forming a colored complex. The intensity of the resulted color was compared to that of an ethalon solution which contained a known quantity of nitrites.

The method's protocol: from the well cut samples $10 \mathrm{~g}$ were measured in a $100 \mathrm{ml}$ flask, and added in $80 \mathrm{ml}$ of distilled water. The samples were left to rest at room temperature for 30 minutes, homogenized with a glass baguette, and then filtered.

In a clean test tube we added: $1 \mathrm{ml}$ of filtered solution, $1 \mathrm{ml}$ of Griess Reactive and $11 \mathrm{ml}$ of distilled water. The sample was left to rest for 20 minutes until the color appears, afterwards the resulted color was compared to the ethalon scale. The quantity of nitrates equaled the number indicated by the test tube from the ethalon scale.

The nitrates determination $\left(\mathrm{NO}_{3}{ }^{-}\right)$

The nitrates are determined through the same method, using the cadmium powder. In parallel two determinations were made: one to determine the nitrites and the second to determine the total nitrate (obtained after the reduction of nitrate to nitrite).

In the two test tubes we added 1-5 $\mathrm{ml}$ of the extract made, and until $19 \mathrm{ml}$ we added water with $1 \mathrm{~g}$ cadmium powder and $5 \mathrm{ml}$ tampon solution; the test tubes were energetically homogenized for 30 minutes; the cadmium powder was separated, than $0.5 \mathrm{ml}$ was added, $20 \mathrm{ml}$ Griess I reactive, respectively Griess II reactive and after 20 minutes the samples were compared at the same wavelength $(\lambda=520 \mathrm{~nm})$.

Volumes of $1-5 \mathrm{ml}$ of extract, mixed with 19 $\mathrm{ml}$ of distilled water were introduced in clean test tubes along with $1 \mathrm{~g}$ of cadmium powder and $5 \mathrm{ml}$ tampon solution. The mix was vortexed rigorously after which the cadmium powder was separated and added 0,5 ml Griess I reagent, respectively $20 \mathrm{ml}$ Griess II reagent. After 20 minutes the samples were interpreted following the control samples at the same wavelength $(\lambda=520 \mathrm{~nm})$. In these conditions the total nitrites content was established. By calculating the difference, the quantity of nitrates equivalent to the nitrites content was found.

For the meat products samples, the evolution in nitrates concentration was followed during a period of 28 days; the monitoring of the concentration was made weekly.

The determination of sodium chloride $(\mathrm{NaCl})$

The silver nitrate $\left(\mathrm{AgNO}_{3}\right)$ in contact with the chlorine ions forms the silver chloride ( $\mathrm{AgCl})$. As indicator we used the potassium chromate. When the chloride is all precipitated under the aspect of silver chloride, the silver nitrate in excess reacts with the potassium chromate $\left(\mathrm{K}_{2} \mathrm{CrO}_{4}\right)$, resulting the silver chromate $\left(\mathrm{Ag}_{2} \mathrm{CrO}_{4}\right)$ which has a brick like color.

The protocol that we followed was: from the same watery extract made for nitrites determination we took $10 \mathrm{ml}$ in an Erlenmeyer glass and added 3-4 drops of potassium chromate. The solution was afterwards titrated with silver nitrate until brick-like color was achieved. The total content of sodium chlorides was expressed in sodium chlorides equivalents. The applied formula was described previously by Mihaiu et al. (2014).

\section{Statistical analysis}

The OriginPro (Software version 8.5, Origin Lab Institute, USA) was used for the ANOVA oneway and the least significant difference test. These 
tests were performed in order to compare the mean values of the nitrates, nitrites and sodium chloride investigated, taking into account also the meat product. Computations Tukey post-hoc means comparison and Levene's test for equal variance were also included. Differences were considered significant at $\mathrm{P}$ values lower than 0.05 . The graphical representations were performed in the same program as the statistical interpretations.

\section{RESULTS AND DISCUSSION}

The samples of meat products investigated showed variable additive concentrations. In the case of the baloney we have found that the producers have respected the maximum allowed concentration (Fig.1). The average of the investigated parameters showed concentration of $\mathrm{NaNO}_{2}^{-}$of $40,86 \mathrm{mg} / \mathrm{kg}, \mathrm{NaCl}=1,38 \%$ and $\mathrm{NH}_{3}=$ $18,51 \mathrm{mg} / \mathrm{kg}$.

In the sausage samples the content varies, but it does not exceed the maximum allowed limits in neither one of the parameters investigated. In the case of chicken sausage the concentration of nitrites had an average of $45.04 \mathrm{mg} / \mathrm{kg}$, with a minimum of $42.04 \mathrm{mg} / \mathrm{kg}$ and a maximum limit of $47.06 \mathrm{mg} / \mathrm{kg}$. The coloring in all the samples investigated had a correspondence for the 4 and 5 etalon test tube which means that it is according to the legislation. The maximum coloring allowed in this case is similar with the $10^{\text {th }}$ test tube from the etalon scale. The sodium chloride showed also variations with a minimum of $1.2 \%$ in a sample collected from the hypermarket and a maximum of $2.7 \%$ which is almost at the limit from another sample collected from a smaller size market. The average in this case was of $1.73 \%$ and none of the samples exceeded the maximum allowed limit of $3 \%$.

The statistical evaluation showed significant differences among the quantities found in the case of poultry baloney and the one processed from pork. Unfortunately in the case of pork baloney there was a sample which exceeded the limits in sodium chloride concentration (Fig. 2). Also, the values found for nitrate and nitrites concentrations were significantly different $(\mathrm{p}<0.05)$ compared to the ones found in chicken baloney. The lowest value found for nitrites was $48.67 \mathrm{mg} / \mathrm{kg}$ and the highest $59.06 \mathrm{mg} / \mathrm{kg}$. The average for this parameter was of $53.92 \mathrm{mg} / \mathrm{kg}$. In the case of nitrates concentration the minimum registered value for pork sausages was of $19.8 \mathrm{mg} / \mathrm{kg}$ and the maximum $22.07 \mathrm{mg} / \mathrm{kg}$ with an average of 20.22 $\mathrm{mg} / \mathrm{kg}$. The markedly higher values registered in pork meat sausages is not very explicable given the fact that both products have a similar processing steps.

In the case of minced meat samples we found that the values were according to the legislation limits. The minimum value registered for $\mathrm{NaNO}_{2}$

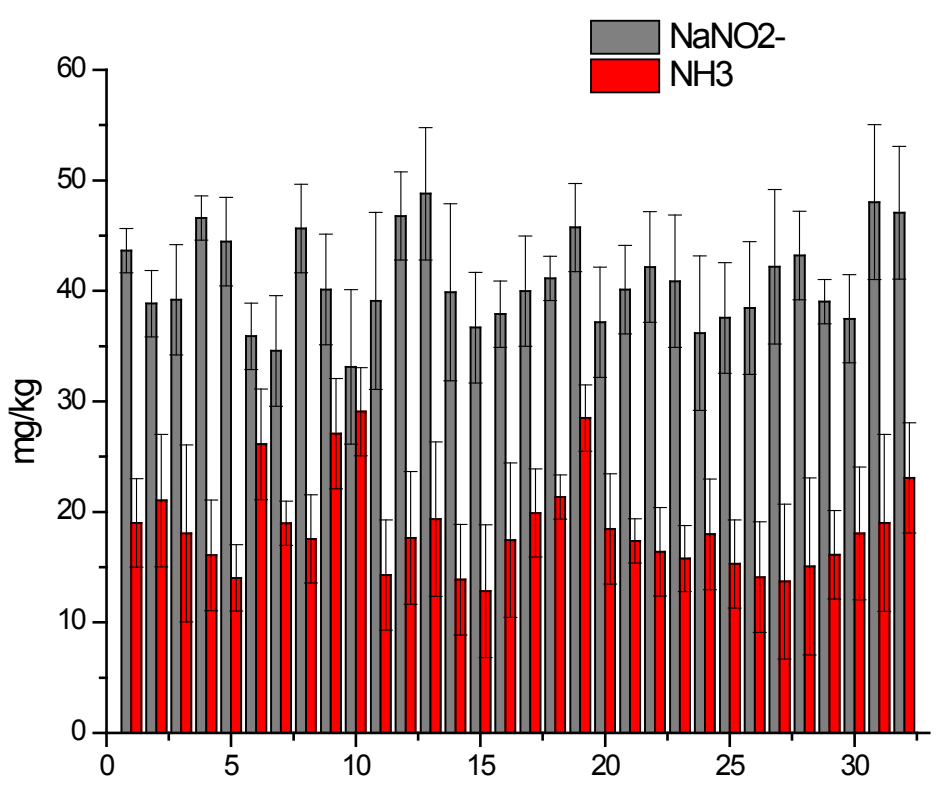

Fig.1. The quantities of nitrates and nitrites found in the baloney samples examined. 


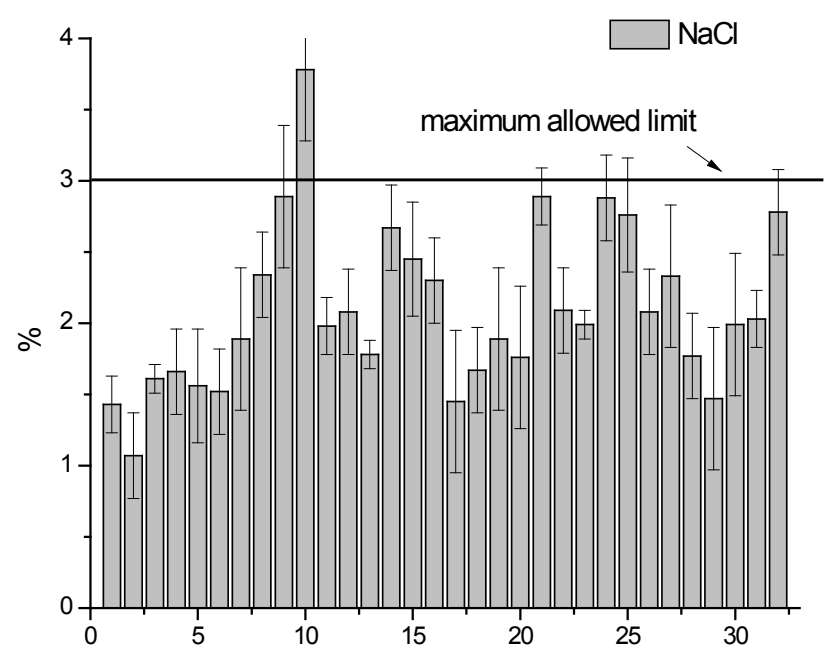

Fig.2. The concentration of $\mathrm{NaCl}(\%)$ found in the pork sausage samples investigated.

was $5.4 \mathrm{mg} / \mathrm{kg}$ and the average registered in this case was below $9.5 \mathrm{mg} / \mathrm{kg}$. The values obtained in this case was statistically different from those found in the other types of products examined $(p<0.05)$ but this might be due to the fact this type of product is less processed and has a shorter shelf life than the rest of the products. The sodium chloride showed similar values to that of the baloney samples, with an average of $1.23 \%$. The nitrates concentration in the minced meat samples showed an average of $20.76 \mathrm{mg} / \mathrm{kg}$.

In a previous study, Mirzaei et al. (2007) revealed nitrate concentration changes during the shelflife of the products, showing that along with the period of preservation the quantity reduces. In another research conducted by Honikel et al. (2008), nitrates level were shown to be reduced in 60 days of storage at cold temperatures. Another study made in Iran in 2001, by Kamkar et al. (2004) revealed an amount of nitrate added that varied between $1-108 \mathrm{ppm}$ in the products that were tested. This shows that there were also samples which exceeded the maximum limit for Europe.

\section{CONCLUSION}

At the analysis of nitrites and nitrates additives concentrations found in meat products, it was revealed that all samples were in conformity with the European regulations. In what concerns the sodium chlorideadding, onesample of porksausage revealed a higher percent than the accepted limit of $3 \%$. In order to ensure the safer consumption of meat products, biochemical analyses are needed to be made on a regular basis in order to determine these additives' concentrations.

\section{REFERENCES}

1. Directive 2006/52/EC of the European Parliament and of the council of 5 July 2006 amending Directive 95/2/EC on food additives other than colours and sweeteners and Directive 94/35/EC on sweeteners for use in foodstuffs.

2. EFSA (European Food Safety Authority) (2010). Statement on nitrites in meat products, EFSA Journal 8(5):1538.

3. Fazio T, Warner CR (1990). A Review of sulphites in foods: analytical methology and reported finding. Food Additives and Contaminants 7:433-454.

4. Honikel KO (2008). The use and control of nitrate and nitrite for the processing of meat products. Meat Science (78): 68-76.

5. Iammarino M (2014). Foodstuffs without Added Food Additives: The Needing of a Normative Update. J Nut Nutr Epd 1(1):1-5.

6. Jiménez Colmenero F, Blazquez J (2007). Additives: Preservatives. In: Nollet L; Toldrá F (Ed). Handbook of Processed Meats and Poultry Analysis. Taylor and Francis, LLC, Boca Raton, USA. (in press).

7. Kamkar A, Hossaini H, Alavi SA, Bahonar AR (2004). Nitrites in meat products. Journal of Research and Development in Livestock and Aquaculture 63:60-65.

8. Karovicová J, Simko P (2000). Determination of synthetic phenolic antioxidants in food by high-performance liquid chromatography. Journal of Chromatography A 882:271281.

9. Mirzaei H, Hosseini H, Rokny N (2007). Journal of Food Science and Technology. Fall 2007 4(3):41-46.

10. Ruiter A, Bergwerff AA (2005). Analysis of chemical preservatives in foods. In : Ötles S (Ed). Methods of analysis of food components and additives, Taylor \& Francis, Boca Raton, FL, chap 14.

11. Wood R, Foster L, Damant A, Key P (2004). Analytical Methods for Food Additives. CRC Press Woodhead Publishing Limited, Boca Raton, Cambridge, 253. 